\title{
UNA NUEVA LOCALIDAD DE GIGASPERMUM MOURETII CORB. (MUSCI) EN LA PENINSULA IBERICA
}

\author{
R. M. ROS
}

\begin{abstract}
RESUMEN: Se da cuenta del hallazgo de Gigaspermum mouretii Corb. en la provincia de Murcia. Es la segunda localidad de esta especie en la Península Ibérica. Anteriormente había sido encontrada por V. Allorge y $C$. Casas en el Cabo de Gata (Almería).
\end{abstract}

SUMMARY: Gigaspermum mouretii Corb. is cited for the first time in Murcia. It was only reported before by $V$. Allorge and C. Casas for Cabo de Gata (Almeria), so it's the second locality for Europe.

Como resultado de numerosas prospecciones por el sureste de la Península Ibérica, dentro de un programa de tesis doctoral, encontré el 19 de febrero de 1983 en la Isla del Ciervo (Cabo de Palos, Murcia) un pequeño musgo, estéril, de difícil identificación. C. Casas que fué tan amable de revisar las muestrasas reconoció que se trataba de Gigaspermum mouretii Corb., musgo perteneciente a la Familia Gigaspermaceae del Orden Funariales.

Esta especie fue descrita por Corbière a partir de un ejemplar procedente de Marruecos (Corbière, 1913), posteriormente se encontraron otras dos localidades, tambien de Marruecos, una de Heim que la encontró en 1934 y otra de Jelenc (1955). Allorge \& Casas (1958), la citaron por primera vez en Europa, en el Cabo de Gata (Almería), en un pequeño barranco en la carretera de Salinas al Faro del Cabo de Gata. Posteriormente (Acuña et al., 1974) fue citada del Cortijo Peralta, cerca de la Rambla de Majada Redonda, en la carretera a la Isleta del Moro (Almería), a $60 \mathrm{msm}$.

Con la nueva localidad se corrobora una vez más su presencia en el sur de España y se amplia su área de distribución en la Península.

Las especies de este género se hallan distribuidas por el hemisferio austral, constituyendo Gigaspermum mouretii una disyunción boreal muy notable, ( $P$. Allorge, 1931 y Casas, Brugués \& Cros, 1981). (Mapa 1).

La Isla del Ciervo está situada en la zona meridional del Mar Menor (30S XG 9970). Es una pequeña isla unida en la actualidad 
a la tierra por una carretera. Está formada por rocas volcánicas neógenas y las características edáficas más sobresalientes son: gran contenido en materia orgánica con un mediano grado de humificación y una acumulación de carbonato cálcico y de arcilla en el horizonte superficial.

Gigaspermum mouretii se ha encontrado formando pequeños céspedes, sobre suelo llano pero pedregoso, protegido por plantas herbáceas y asociado a Fissidens viridulus, Bryum ruderale y Riccia sorocarpa.

Debido a que esta especie no se halla incluida en ninguna flora europea y a la ausencia de dibujos y medidas que acompañen a la descripción original (Corbière, op. cit.), se ha considerado interesante realizar una sucinta descripción que facilite su identificación.

Los tallitos de color verde amarillento a verde blanquecino, salen de un rizoma muy desarrollado, a menudo ramificado, suelen medir de 5,5 a $8,1 \mathrm{~mm}$ de altura. Las hojas se disponen helicoidalmente en el tallo, cóncavas, suborbiculares a ovoidales, oscilan de 520-770 $\mu \mathrm{m}$ de ancho y de 790-840 $\mu \mathrm{m}$ de largo. El margen es plano, el ápice obtuso o redondeado, con un mucrón piliforme hialino, que puede oscilar de 170-298 $\mu \mathrm{m}$ de largo, compuesto de dos células basales largamente hexagonales y otra célula apical linear o fusiforme. Las células de las hojas suelen ser hexagonales; las de la base son casi rectangulares, de 35-84 x $(17,5) 28-38,5 \mu \mathrm{m}$; las del centro de la hoja de (35) 42-66,5 x $(17,5)$ 21-31,5 $\mu \mathrm{m}$ y las superiores de $(24,5) \quad 35-52,5 \times(17,5) 21-31,5 \mu \mathrm{m}$. Las células exteriores del tallo son largamente rectangulares, de 84-175 (245) x 31,5-56 (66,5) $\mu \mathrm{m}$ y se desgarran fácilmente al arrancar las hojas. (Fig. 1). Todos los tallos son estériles y en España siempre se ha recolectado en este estado.

Un ejemplar está depositado en el herbario del Departamento de Botánica de la Universidad de Murcia y otro en el Herbario del Departamento de Botánica de la Universidad Autónoma de Barcelona ( $\mathrm{BCB})$.

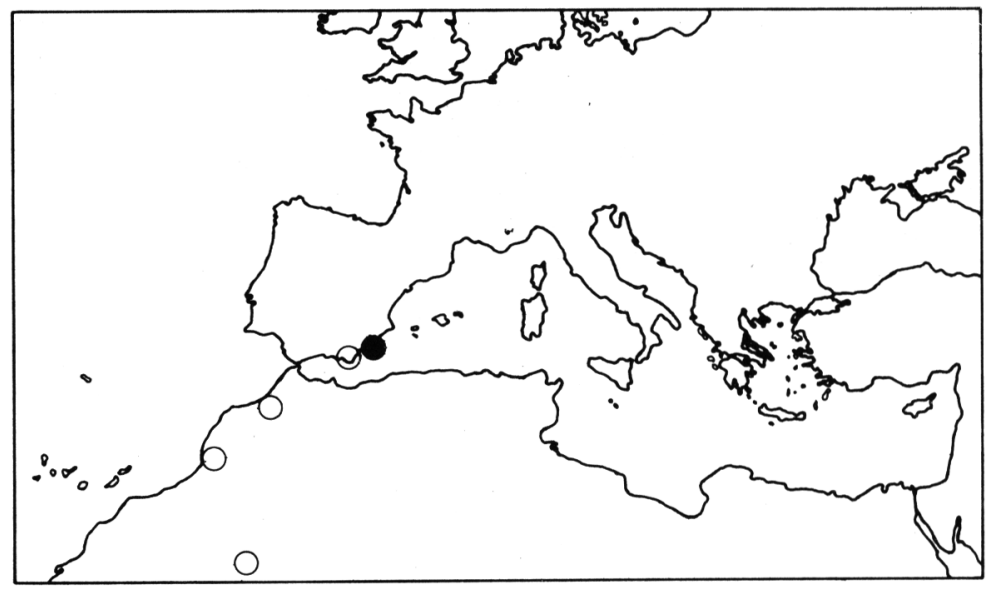

Mapa 1.- Distribución de Gigaspermum mouretii Corb. (Círculos): Citas bibliográficas. (Punto negro): Nueva cita. 
Gigaspermum mouretii Corb.
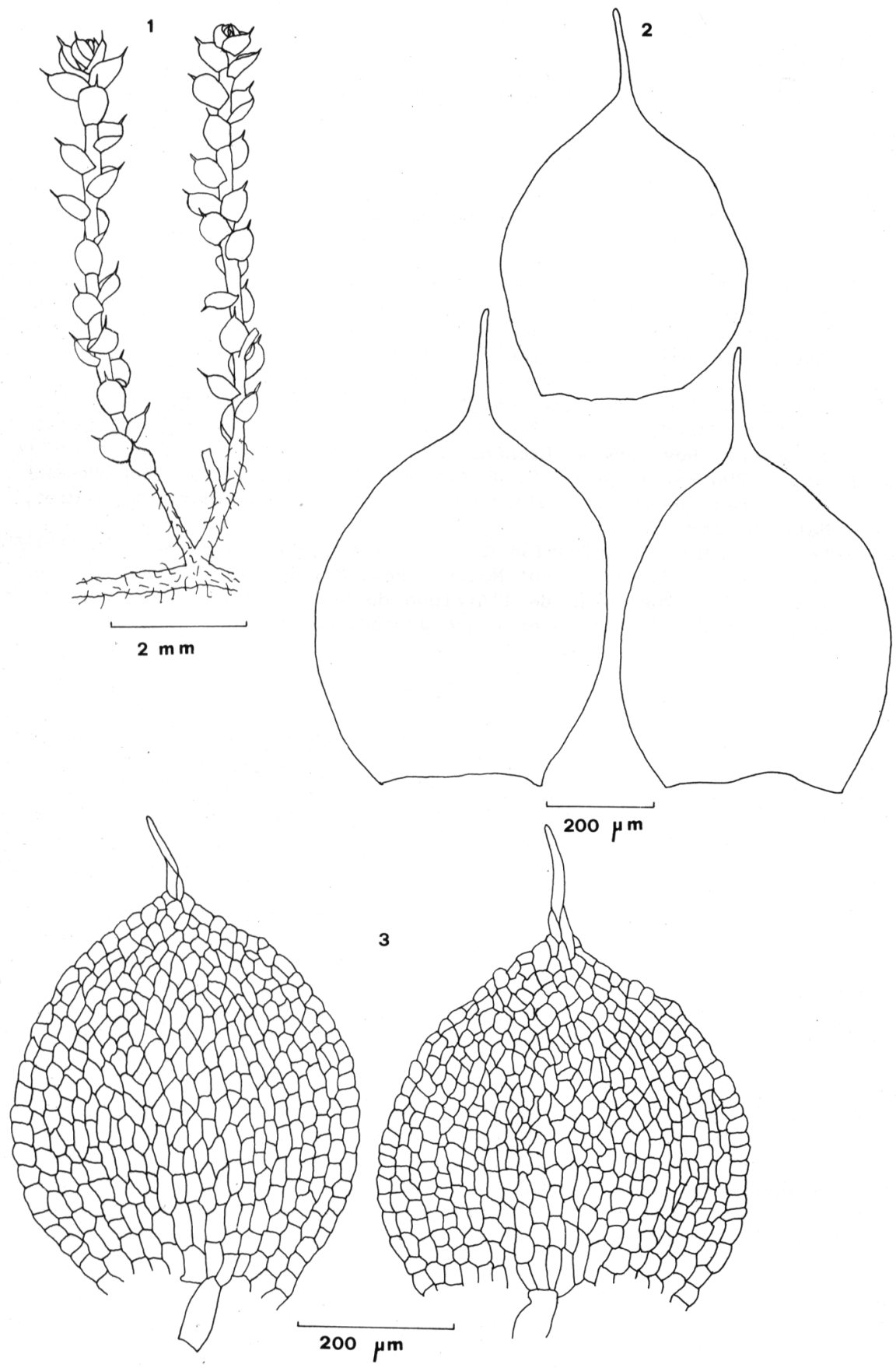

Figura 1.- Gigaspermun mouretii Corb. 1: Aspecto de la planta en estado húmedo. 2: Filidios. 3: Areolación de los filidios. 


\section{AGRADECIMIENTO}

Mi más sincero agradecimiento a la Dra. C. Casas que determinó la especie y me ha facilitado datos y bibliografía para la realización de esta nota.

\section{BIBLIOGRAFIA}

ACUÑA, A., CASAS, C., COSTA, M., FUERTES, E., LADERO, M. , LOPEZ, M.L. , SIMO, R.M. \& VARO, J. -1974- Aportaciones al conocimiento de la flora briológica española. Nótula I: El Cabo de Gata (Almería). Anal. Inst. Bot. Cavanilles, 31(2): 59-95.

ALLORGE, P. -1931- Sur quelques types de disjonctions dans la flore muscinale ibérique. Travaux Cript. a L. Manguin, 465-475.

ALLORGE, V. \& CASAS, C. -1958- Contribution à la flore bryologique de l'Espagne. Rev. Bryol. Lichénol., 27 (1-2): 55-65.

CASAS, C., BRUGUES, M. \& CROS, R.M.-1981- Contribució al coneixement de l'àrea geogràfica d'alguns briòfits. Treb. Inst. Cat. Hist. Nat., 9: 169-178.

CORBIERE, L. -1913- Contribution à la Flore bryologique du Maroc d'après les recoltes du Lieutenant Mouret. Rev. Bryol., 40: 10-11.

JELENC, F. -1955- Muscinées de l'Afrique du Nord. Extrait du Bull. Soc. Géogr. et d'Arch. de la province d'Oran. $125 \mathrm{pp}$.

Dirección de la autora: Departamento de Botánica, Facultad de Ciencias, Universidad de Murcia (España). 